\title{
EDITORIAL
}

\section{An overview of educational challenges and responses to the global COVID-19 pandemic in pharmacy schools in Turkey}

\author{
Aysu Selcuk ${ }^{1}$, Gulbin Ozcelikay $^{2}$ \\ ${ }^{1}$ Department of Clinical Pharmacy, Faculty of Pharmacy, Ankara University, Turkey \\ ${ }^{2}$ Department of Pharmacy Management and History, Faculty of Pharmacy, Ankara University, Turkey
}

\author{
Correspondence \\ Aysu Selcuk \\ Ankara University \\ Faculty of Pharmacy \\ Department of Clinical \\ Pharmacy \\ Emniyet Mah. Degol Cd. No: 4 \\ Postal code: 06560 \\ Yenimahalle \\ Ankara \\ aysuselcuk@ankara.edu.tr
}

\begin{abstract}
Education is one of the areas affected by COVID-19. The authorities in Turkey responded fast to COVID-19 with the continuation of distance learning in higher education after 13 days of the first case. It was the first time pharmacy schools provided distance learning in Turkey. Although, in the beginning, there were some problems, students and academic staff adopted an online platform in a few weeks. Surveys completed by students and academic staff demonstrated that distance learning could provide opportunities for students such as easy access to lecture notes and repetition of lectures, and for academic staff improved working environment, flexibility and time-saving. However, both students and academic staff do not agree that face-to-face education should be replaced with distance learning. Using online platforms for distance learning in response to COVID-19 has enlightened faculty in terms of adopting new technology and educational techniques in lectures.
\end{abstract}

The Council of Higher Education (YOK) is the principal authority in Turkey that plans, evaluates, and standardises higher education. It produces rules and regulations for all universities that are affiliated. When the first case of coronavirus disease 2019 (COVID-19) was seen in Turkey on 10th March 2020, the Ministry of Health provided a list of recommendations for many sectors and situations including higher education. Since 23rd March, 2020, it has been nationally decided to continue higher education with distance learning for at least the entire semester and for the next semesters if necessary. In Turkey, there are thirty-eight pharmacy faculties providing undergraduate education. Some of the universities already had distance learning platforms, but generally not for the faculties of pharmacy. After this decision, these existing online platforms were updated for all faculties. Those that did not have distance learning platforms opted to use publicly available platforms. This was a very rapid response and adaptation for higher education in Turkey under COVID-19 circumstances. This is also the first time that pharmacy schools are embracing distanced and remote learning in Turkey together with new technical and staff related issues.

Most of the universities established a website to inform the public and students about COVID-19 updates such as the number of cases, announcements, international publications, prevention strategies, appropriate diet and supplementation, how to protect mental health during the pandemic, and action plan for a working environment. 
Some of the suggestions of the action plan in our faculty included mandatory use of personal protective equipment and using disinfectant, measuring body temperature while entering the buildings and routine disinfection of common areas. There is also social restriction such as shaking hands. Since COVID-19, shift work among the university staff or working from home was also applied twice depending on the number of cases in the country and the availability of the staff's position/work.

There were some students who were from rural areas where the internet connection was poor and foreign students whose time zones were different than Turkey's to actively participate in lectures. There were also students who had to share their laptops or other electronic devices with their siblings since all education became online in the country. It is likely to cause inequities among the students. To minimise inequalities in higher education, students were allowed to suspend their enrolment to continue after the pandemic without any penalty. Students were keen to continue their education because they had access to lecture notes and recordings of each lecture. Although some students were not able to attend live lectures, they were allowed to ask questions or share their concerns/questions via the education platform or email module coordinators. There were at least two staff appointed to answer students' concerns regarding online education in each faculty in Ankara University. Some of the concerns were related to the IT department such as connection or system access problems and some were related to the faculty such as sharing lecture notes and adapting the new schedule according to distance learning. The faculty staff and IT department responded to students' concerns on time. Most of the undergraduate students adapted well within the first two weeks of online pharmacy higher education. Additionally, academic staff had further instruction and support to enable rapid adoption quickly.

A survey was conducted in our faculty to evaluate students' perceptions of these new introductions to distance learning experience at end of the semester. A total of 535 students responded to the survey (Ankara University, 2020). According to the survey results, $83 \%$ of the students had prior experience or training about distance learning (Ankara University, 2020). They agreed or strongly agreed that they can easily access distance learning via their phones or laptops or other electronic devices (63\%), lecture contents (57\%), recorded lectures that they did not attend in person (82\%). (Ankara University, 2020). They indicated that they know how to use the platform (78\%) and the platform provided the opportunity to repeat lectures when this was needed
(82\%) (Ankara University, 2020). The majority of the students agree or strongly agree that distance learning should not replace face to face education (78\%) and did not perceive distance learning as an effective education model (83\%) (Ankara University, 2020). This perception about distance learning might have been affected by students' limited access to internet or online resources or not asking questions about the lectures or not receiving answers from the teaching staff on time.

In our pharmacy school, most of the attending students were from cities other than that where they are registered for university education. Therefore, they were unable to attend university for mid-term or final examinations or modules requiring laboratory practice. The laboratory modules were conducted online but the faculty has now developed plans to invest in advanced online training programmes for laboratory modules in the future. The midterm exams were changed to 'homework submissions' and final exams were done via the online platform. This may have affected the quality of the education but it was considered the best strategy to avoid problems such as delayed graduation due to not taking exams, or having to increase the number of modules in the next semester if students do not take the module according to the academic plan. However, graduate students' access to laboratories was continued. They were able to continue their work using personal protective equipment and laboratory schedules, which were planned according to COVID-19 circumstances and allowed only a limited number of students in the laboratory.

Besides the inability to conduct face-to-face courses, exams and laboratory modules, another issue was how to perform pharmacy internships for undergraduate and graduate students. The decision to continue the internships under protective measures or to continue through distance learning was a decision made by the universities rather than by YOK. Some pharmacy schools continued online students' services, such as medication review, which is provided during their postgraduate internship. They contacted healthcare professionals via phones or online platforms to help with medicationrelated problems. In these pharmacy faculties, at least one student was on-call to provide solutions on medicationrelated problems during COVID-19. However, due to individual decisions by universities, the on-site training of graduate and postgraduate students was not possible. This might decrease their adaptation into the pharmacy workforce in the future. Due to lack of interaction between peers and seniors, students' motivation about their career and learning new skills, which they have not practiced, might decrease. 
The teaching/academic staff responded well to the rapid implementation of online education. Online videos and conferences were conducted by the university to teach and answer questions from academic staff about using distance learning platforms. A survey was conducted including 168 respondents from 13 pharmacy faculties in Turkey during the first distance learning semester (Calikusu \& Ozcelikay, 2020). The national survey evaluated academic staff's attitudes, self-efficacy and understanding about the benefit of distance learning. The more senior academic staff, such as professors, tended to state that face to face interaction is more effective in the provision of the better educational practice (Calikusu \& Ozcelikay, 2020). Younger academic staff, including research assistants and assistant professors, tended to perceive that distance learning is more time-efficient and provides working space flexibility (Calikusu \& Ozcelikay, 2020). They feel more competent in preparing various course materials for effective distance learning compared to the older academic staff (Calikusu \& Ozcelikay, 2020). Although it was not stated in the survey, there were inequalities among the academic staff in terms of technology usage. The younger generation are likely to learn easily, use without help and try the other features of the online education platform. Gender inequalities based on number of new grand submissions among academic staff are demonstrated in other countries. In Turkey, there are no available public/academic sources to show similar trends yet.

During the pandemic, important and urgent meetings were conducted online in our faculty. The attendance was high for these meetings. Student representatives from each class joined the meetings to share their problems with online education so that academic staff could find solutions. Therefore, online education did not appear to affect the communication between students and academic staff in those early challenging weeks.

Education during COVID-19 has enlightened to us how we can use technology for education and communication. It has shown that students and academic staff can adapt to digital technology successfully. It has also increased the awareness of students and academic staff as to how online resources such as videos, useful links, or other educational platforms can be used in lectures. However, there is room for improvement in the quality of online education as the students and many academic staff continue to view distance learning as less effective compared with face to face education.

\section{References}

Ankara University. (2020) Newsletter of Ankara University Faculty of Pharmacy. Issue no: 53. Available at: http://www. pharmacy.ankara.edu.tr/e-bulten/vil-6-2020-e-bulten/

Calikusu, M., \& Ozcelikay, G. (2020). Attitude, self-efficacy and benefit perception of the teaching staff of pharmacy schools for distance education. Pharmacy Innovations, Eczaclikta Yenilikler 3, Ankara Üniversitesi Yayınları Yayın No. 127, 133-144 